\title{
EFEKTIFITAS PENYULUHAN DENGAN MENGGUNAKAN MEDIA LEAF LET DAN VIDEO BAHASA DAERAH TERHADAP PENGETAHUAN BAHAYA ROKOK PADA REMAJA
}

\author{
Andan Firmansyah $^{1}$, Ahid Jahidin ${ }^{2}$, Nur Isriani Najamuddin ${ }^{3}$ \\ ${ }^{1}$ Dosen Keperawatan STIKES Bina Generasi Polewali \\ ${ }^{2}$ Dosen Keperawatan STIKES Bina Generasi Polewali \\ ${ }^{3}$ Staf Program Studi Ilmu Keperawatan STIKES Bina Generasi Polewali Mandar
}

\begin{abstract}
ABSTRAK
Latar belakang : Rokok sudah sangat terkenal dan tidak asing lagi bagi seluruh kalangan, hampir seluruh kalangan baik orang dewasa, remaja bahkan anak-anak pasti sebagian besar pernah mengisap batang rokok. Sebagian besar perokok sudah mengetahui dampak dan bahaya dari rokok itu sendiri, bahkan disetiap bungkus rokok sudah menyebutkan bahaya rokok itu sendiri, namun sebagian orangorang tetap tidak menghiraukannya. Proses penyuluhan kesehatan dalam mencapai tujuan melalui perubahan perilaku remaja yang dipengaruhi oleh beberapa faktor diantaranya yaitu materi atau pesan yang disampaikan alat peraga, metode dari petugas atau pendidik yang melakukan promosi kesehatan serta bahasa yang digunakan.
\end{abstract}

Tujuan: Tujuan penelitian ini untuk mengetahui efektifitas penggunaan media leaflet bahasa daerah dan video bahasa daerah terhadap pengetahuan remaja tentang bahaya rokok.

Metode : Jenis penelitian ini adalah Quasi Eksperimen dengan rancangan penelitian Pretest and Posttest two Group Design dengan menggunakan media leaflet bahasa daerah dan video bahasa daerah sebagai bentuk edukasi pada 120 remaja. Pengukuran pengetahuan pre-test dan post-test menggunakan kuesioner kemudian dilakukan analisis dengan uji wicoxon.

Hasil : Ada perbedaan pengaruh antara kelompok leaflet bahasa daerah dan video bahasa daerah, dimana nilai $\mathrm{p}=0.000 \leq \alpha=0,05$, diketahui mean sesudah penyuluhan menggunakan media leaflet bahasa daerah sebesar 1,98 sedangkan nilai mean sesudah penyuluhan media video bahasa daerah sebesar 2,32.

Kesimpulan : Kedua penggunaan media leaflet bahasa daerah dan video bahasa daerah sama efektif dalam meningkatkan pengetahuan remaja tentang bahaya merokok.

Kata Kunci ～: Rokok, Pengetahuan, Penyuluhan, Leaflet, Video, Bahasa Daerah

\begin{abstract}
Background: Cigarettes are very well known and familiar to adults, better for adults, teenagers and even children Most smokers already know about the dangers and dangers of cigarettes themselves, even if the cigarette packets are set up already carry out the dangers of cigarettes themselves, but the majority of people still ignore it. The process of directing health in achieving its goals through changing the perspective of adolescents is carried out by a number of introductory factors or material delivered props, methods from officers or educators who carry out health promotion and the language used.

Objective: The purpose of this study is to study the effectiveness of the use of language leaflets and local language videos on adolescent knowledge about the dangers of smoking.

Method: This type of research is a Quasi Experiment with a Pretest and Posttest two Group Design research design using language leaflets and local language video as a form of education for 120 teenagers. Measurement of pre-test and post-test knowledge using a questionnaire and then analyzed with the wicoxon test.
\end{abstract}


Results: There was a difference between the local language leaflet group and the local language video, where the value of $p=0,000 \alpha \alpha=0.05$, understood to mean agreed by using local language leaflet media of 1.98 while the average value was updated 2.32 .

Conclusion: Both the use of local language leaflets and regional language videos are equally effective in increasing adolescent knowledge about the dangers of smoking.

\section{Keywords: lecturer, promotion, position}

\section{PENDAHULUAN}

Merokok merupakan kegiatan yang sering kita jumpai di masyarakat. Tidak hanya masyarakat di Indonesia tetapi juga masyarakat di dunia. World Health Organization (WHO) melaporkan bahwa pada tahun 2010 terdapat satu miliar orang pengguna produk tembakau di seluruh dunia (Aliansi Pengendalian Tembakau Indonesia, 2013). Distribusi konsumsi rokok di dunia pada tahun 2014 masih sangat tinggi yaitu berjumlah 5,8 triliun. China menempati urutan pertama dan Indonesia menempati urutan ketiga di dunia. Dampak buruk rokok juga akan dirasakan oleh orang-orang yang menghirup asap rokok di sekitarnya (secondhand smoke). Anak-anak penderita asma di Amerika pada tahun 2010- 2011 dilaporkan bahwa yang terkena paparan asap rokok sebanyak 35\% kasus, sedangkan hasil tes laboratorium menunjukkan jumlah yang lebih banyak yaitu sebesar $80 \%$. Terdapat 162.200 kasus penyakit yang diderita oleh secondhand smoke pada anak-anak diantaranya terdapat 20.000 penderita penyakit saluran pernafasan bawah, 120.000 penyakit telinga tengah, 22.000 penyakit asma dan 200 kasus meningitis (Eriksen, et al, 2015).

Masa remaja adalah masa transisi, dimana pada masa - masa seperti ini sering terjadi ketidakstabilan baik itu emosi maupun kejiwaan. Pada masa transisi ini juga remaja sedang mencari jati diri sebagai seorang remaja (Nurihsan, 2011) Peningkatan konsumsi rokok pada remaja seakan mengabaikan bahaya yang akan ditimbulkan rokok bagi kesehatan, padahal, banyak penyakit yang diakibatkan oleh rokok, seperti : kangker mulut, kangker rahim, kangker paru, kanker prostat, gangguan kehamilan dan janin, penyakit jantung koroner, pneumonia, dan lainnya (sriamin 2006). Rokok membunuh 1 Dari 10 orang dewasa di seluruh dunia dengan angka kematian dini mencapai 5,4 juta jiwa pada tahun 2005 (canggih, 2012). Faktor yang dapat mempengaruhi kebiasaan merokok pada remaja diantaranya adalah pola asuh orang tua, pengaruh teman sebaya yang merokok, tayangan iklan rokok, dan kebutuhan aktualisasi diri, tekanan atau ejekan oleh teman sebaya jika tidak merokok (Depkes RI, 2010).

Semua ahli kesehatan termasuk World Health Organization (WHO) telah lama menyimpulkan, bahwa secara kesehatan rokok banyak menimbulkan dampak negatif, lebih bagi anak-anak dan masa depannya. Rokok mengandung 4000 zat kimia dengan 200 jenis di antaranya bersifat karsinogenik (dapat menyebabkan kanker), di mana bahan racun ini didapatkan pada asap utama yaitu asap rokok yang terhisap langsung masuk keparu-paru perokok maupun asap samping yaitu asap rokok yang dihasilkan oleh ujung rokok yang terbakar, misalnya karbon monoksida, benzopiren, dan amoniak (KPAI, 2013).

Dengan meningkatkan pengetahuan remaja tentang bahaya merokok melalui pendidikan kesehatan, diharapkan mereka dapat menghentikan kebiasaan merokok dan menghindari rokok bagi yang belum pernah mengkonsumsinya. Pendidikan kesehatan sangat diperlukan untuk menggugah kesadaran memberikan atau meningkatkan pengetahuan masyarakat tentang pemeliharaan dan peningkatan kesehatan baik bagi dirinya sendiri, keluarga maupun masyarakat. Proses pendidikan kesehatan dalam mencapai tujuan melalui perubahan perilaku remaja yang dipengaruhi oleh beberapa faktor diantaranya yaitu materi atau pesan yang disampaikan alat peraga pendidikan yang dipakai, metode yang digunakan serta petugas atau pendidik yang melakukan promosi kesehatan. Pengetahuan seseorang akan mempengaruhi gaya hidupnya untuk berperilaku sehat, seseorang yang dipenuhi banyak informasi (pengetahuan) akan mempersepsikan informasi tersebut sesuai dengan sifat psikologinya. Wawasan yang luas dan memadai tentang bahaya rokok bagi kesehatan diharapkan dapat menjadi prinsip seseorang untuk membuat orang yang belum merokok tetap tidak merokok dan para pecandu rokok dapat menghentikan kebiasaan yang berbahaya ini (Putri, 2010).Menurut 
Notoatmodjo (2012) metode dan teknik pendidikan kesehatan adalah cara dan dengan menggunakan alat atau teknologi yang digunakan untuk menyampaikan rangkaian materi pendidikan kesehatan. Metode ceramah, digunakan untuk sasaran kelompok (kelompok besar dan kecil),dapat dibantu dengan slide, video ataupun film. Sedangkan untuk kelompok kecil dengan metode ceramah ataupun menggunakan metode diskusi kelompok, dan brainstorming (curah pendapat) serta menggunakan alat bantu : slide, video, lembar balik dan sebagainya. Metode tidak langsung seperti dengan berbincang-bincang (talk) penyebaran leaflet, poster, spanduk, dan sebagainya.

Hasil studi pendahuluan yang dilakukan oleh peneliti pada tanggal 25-26 Desember 2017. Melalui wawancara dengan kepala desa, beliau mengatakan bahwa sudah pernah dilakukan penyuluhan oleh petugas kesehatan mengenai bahaya rokok dengan media kesehatan yang menggunakan bahasa Indonesia namun tidak ada perubahan terhadap sikap merokok pada remaja, bahkan jumlah perokok remaja khususnya laki-laki semakin bertambah. Dilakukan pula wawancara dengan 10 orang remaja laki-laki dan 10 orang perempuan yang diambil secara acak dari 8 dusun yang ada. Dari 10 orang remaja laki-laki 9 diantaranya mengaku perokok aktif Sedangkan dari 10 orang remaja putri yang 3 diantaranya mengaku pernah mengisap rokok. Diantara 20 remaja tersebut semuanya mengaku tidak banyak mengetahui tentang bahaya rokok dan belum pernah mendapatkan penyuluhan kesehatan tentang bahaya yang ditimbulkan oleh rokok. Jumlah remaja di desa kala'be sendiri sebanyak 120 orang terdiri dari 50 lakilaki dan 70 perempuan.

Dilakukan pula pengkajian informasi disekolah-sekolah yang ada di kecamatan Aralle antara lain SMP N 1 Aralle dan SMA N 1 Aralle melalui wawancara dengan wakil kepala sekolah bagian kesiswaan. Di dapatkan informasi bahwa sekolah-sekolah di kecamatan Aralle khususnya SMP dan SMA telah diberlakukan konsekuensi kepada siswa yang terbukti merokok dilingkungan sekolah. Konsekuensi yang diberikan berupa teguran dengan dilakukan pemanggilan orang tua/wali siswa. Dan apabila siswa tersebut melakukan kesalahan yang sama sebanyak tiga kali maka pihak sekolah akan mengeluarkan siswa yang bersangkutan dari sekolah.

Mengingat keragaman kultur budaya di Indonesia, tentunya akan ada sejumlah factor penghambat dimana bahasa, symbol dan lambang-lambang yang terkomunikasikan mengalami proses panjang sebelum memberikan pengaruh balik terhadap bahasa, simbol dan lambang-lambang yang dimaksudkan (Asi, \& Sambas, 2015). Sehingga menurut calon peneliti perlu dirancang media yang sesuai dengan kebutuhan dan nilai-nilai social budaya masyarakat sehingga pesan yang dapat lebih efektif untuk merubah pengetahuan remaja khususnya bahaya rokok. Hasil observasi yang dilakukan oleh calon peneliti, didapatkan bahwa seluruh komunikasi didaerah ini masih menggunakan bahasa daerah Aralle. Bahkan komunikasi disekolah baik antara murid dengan maupun antara guru dengan murid masih menggunakan bahasa daerah. Hal tersebut membuat peneliti tertarik untuk melakukan penelitian dengan mengangkat judul penelitian "Efektifitas penyuluhan dengan menggunakan Media Leaflet dan Video bahasa daerah Terhadap Pengetahuan Bahaya Rokok Pada Remaja Di Desa Kala'be Kecamatan Aralle Kabupaten Mamasa".

\section{METODE}

\section{Jenis Penelitian}

Jenis penelitian ini adalah quasi eksperimen, dengan rancangan penelitian two group, Pre test and Post tes design. Dengan maksud untuk menguji bagaimana efektifitas media leaflet bahasa daerah dan video bahasa daerah terhadap pengetahuan bahaya rokok pada remaja

\section{Lokasi dan Waktu Penelitian}

Penelitian ini berlokasi di beberapa Sekolah SMA yang ada di desa Kala'be Kecamatan Aralle Kabupaten Mamasa. Penelitian dilaksanakan pada bulan Maret - Juli 2019

\section{Populasi dan Sampel.}

Populasi dalam penelitian ini ialah remaja yaitu sebanyak 200 orang remaja. Penelitian ini dilakukan pada seluruh populasi atau tekhnik total sampling.

\section{Pengumpulan Data}

Pengumpulan data dilakukan dengan menggunakan kusioner (angket) bahasa daerah 
tentang bahaya rokok pada remaja dengan empat pilihan jawaban. Setelah diperoleh data dari responden kemudian di uji dengan uji korelasi antara skor (nilai) tiap-tiap item (pertanyaan) dengan skor total kuesioner tersebut. Dengan uji korelasi sebanyak jumlah pertanyaan yang diajukan. Adapun teknik korelasi yang dipakai adalah teknik Correlated Item-Total Correlation yang diuji melalui program SPSS 21. Kuesioner awal berjumlah 34 butir, setelah dilakukan uji validitas hanya 29 butir yang dinyatakan valid dan 5 butir dinyatakan tidak valid. Butir yang tidak valid karena memiliki nilai $r$ hitung lebih rendah dari $\mathrm{r}$ tabel yaitu 0,339. Rentang nilai hasil uji validitas antara $0,352-0,725$. Pernyataan yang tidak valid dikeluarkan dari daftar sebelum dilakukan uji reliabilitas. Uji reliabilitas dilakukan terhadap 29 butir dan berdasarkan hasil uji seluruh pernyataan dinyatakan reliabel dengan nilai $r$ hitung lebih besar dari nilai $r$ tabel. Seluruh pernyataan dinyatakan reliabel dengan hasil uji statistik Alpa Cronbach dengan rentang nilai antara $0,668-0,706$.

\section{Pengolahan dan Analisis Data}

Pengelompokan dilakukan dengan membuat total skor masing-masing komponen penilaian untuk masing-masing dosen kemudian ditentukan nilai Meannya. Apabila skor nilai masing-masing dosen kurang dari Mean maka diberi kategori baik dan apabila lebih dari atau sama dengan Mean dikategorikan kurang baik. Data selanjutnya dianalisis distribusi frekuensi, Chi-Square dan Regresi Logistik.

\section{HASIL}

Distribusi Responden Kelompok Media Leaflet Bahasa Daerah Berdasarkan Jenis Kelamin

Tabel 4.1

Distribusi Responden Berdasarkan Jenis Kelamin Kelompok Media Leaflet Bahasa Daerah

\begin{tabular}{llll}
\hline No. & Jenis kelamin & $\boldsymbol{F}$ & $\mathbf{( \% )}$ \\
\hline 1 & Perempuan & 120 & 66,7 \\
\hline 2 & Laki-laki & 80 & 33,3 \\
\hline Jumlah & & $\mathbf{2 0 0}$ & $\mathbf{1 0 0}$ \\
\hline
\end{tabular}

Sumber : Data Primer 2018

Berdasarkan tabel 4.1 menunjukan bahwa responden pada kelompok media leaflet bahasa daerah distribusi tertinggi adalah jenis kelamin perempuan sebanyak 120 orang $(66,7 \%)$ dan terendah adalah berjenis kelamin laki-laki sebanyak 80 orang $(33,3 \%)$. Distribusi responden kelompok media video bahasa daerah berdasarkan jenis kelamin bisa di lihat pada tebel dibawa ini :

Tabel 4.2

Distribusi Responden Berdasarkan Jenis Kelamin Kelompok Media Video Bahasa Daerah

\begin{tabular}{cccc}
\hline No. & Jenis kelamin & $\boldsymbol{F}$ & $\mathbf{( \% )}$ \\
\hline 1 & Perempuan & 100 & 50,0 \\
\hline 2 & Laki-Laki & 100 & 50,0 \\
\hline & Jumlah & $\mathbf{2 0 0}$ & $\mathbf{1 0 0}$ \\
\hline
\end{tabular}

Sumber : Data Primer 2018

Berdasarkan tabel 4.2 menunjukan bahwa responden pada kelompok media video bahasa daerah distribusi jenis kelamin perempuan sebanyak 100 orang $(50,0 \%)$ dan terendah adalah berjenis kelamin laki-laki sebanyak 100 orang $(50,0 \%)$.

Distribusi responden berdasarkan tingkat pengetahuan penyuluhan menggunakan media leaflet bahasa daerah bisa di lihat pada tebel dibawa ini :

Tabel 4.3

Distribusi Responden Berdasarkan Tingkat Pengetahuan Remaja Sebelum dan sesudah Penyuluhan Menggunakan Leaflet Bahasa

\begin{tabular}{lccc}
\hline No & Pengetahuan & $\boldsymbol{F}$ & $\boldsymbol{\%}$ \\
\hline \multicolumn{1}{l}{ Sebelum } & & & \\
\hline 1 & Kurang & 94 & 53,3 \\
\hline 2 & Cukup & 64 & 28,3 \\
\hline 3 & Baik & 42 & 18,3 \\
\hline Sesudah & & & \\
\hline 1 & Kurang & 44 & 36,7 \\
\hline 2 & Baik & 85 & 35,0 \\
\hline 3 & Cukup & 71 & 28,3 \\
\hline & Jumlah & $\mathbf{2 0 0}$ & $\mathbf{1 0 0}$ \\
\hline
\end{tabular}

Sumber : Data Primer 2018

Berdasarkan tabel 4.5 diatas menunjukan bahwa sebelum dilakukan penyuluhan mengguanakan media video bahasa daerah mayoritas responden dengan pengetahuan kurang sebanyak 94 (53,3\%), Pengetahuan cukup sebanyak $64(28,3 \%)$ dan pengetahuan baik sebanyak $42(18,3 \%)$ Sedangkan tingkat pengtahuan remaja Sesudah dilakukan penyuluhan menunjukkan pengetahuan kurang sebanyak 44 (36,7\%), Pengetahuan cukup 
sebanyak $71(28,3 \%)$ Sedangkan pengetahuan baik sebanyak $85(35,0 \%)$

Distribusi responden berdasarkan tingkat pengetahuan penyuluhan menggunakan media Video bahasa daerah bisa di lihat pada tebel dibawa ini :

Tabel 4.4

Distribusi Responden Berdasarkan Tingkat Pengetahuan Remaja Sebelum dan sesudah Penyuluhan Menggunakan Video Bahasa daerah

\begin{tabular}{|c|c|c|c|}
\hline No & Pengetahuan & $F$ & $\%$ \\
\hline \multicolumn{4}{|c|}{ Sebelum } \\
\hline 1 & Kurang & 45 & 75,0 \\
\hline 2 & Cukup & 8 & 13,3 \\
\hline 3 & Baik & 7 & 11,7 \\
\hline \multicolumn{4}{|c|}{ Sesudah } \\
\hline 1 & Kurang & 37 & 61,7 \\
\hline 2 & Baik & 12 & 20,0 \\
\hline \multirow[t]{2}{*}{3} & Cukup & 11 & 18,3 \\
\hline & Jumlah & 200 & 100 \\
\hline
\end{tabular}

Sumber : Data Primer 2018

Berdasarkan tabel 4.4 diatas diketahui bahwa sebelum dilakukan penyuluhan menggunakan media video bahasa daerah mayoritas responden dengan pengetahuan baik sebanyak 7 (11,7\%), sedangkan pengetahuan kurang sebanyak $45(75,0 \%)$ dan pengetahuan cukup sebanyak $8(13,3 \%)$. Sedangkan setelah dilakukan penyuluhan menggunakan media video bahasa daerah didapatkan responden dengan pengetahuan kurang sebanyak 37(61,7\%), pengetahuan baik $12(20,0 \%)$, dan pengetahuan cukup 11(18,3\%).

Analisis Perbedaan Pengetahuan Sebelum dan Sesudah Penyuluhan Menggunakan Media Leaflet Bahasa Daerah

Tabel 4.7

Efektifitas penggunaan Media Leaflet Bahasa Daerah dalam Meningkatkan Pengetahuan Bahaya Rokok Pada Remaja di Desa Kala'be Kec. Aralle Kab. Mamasa

Kelompok Media Leaflet $\quad$ Mean $\quad P$ Bahasa Daerah

\begin{tabular}{cccr}
\hline Pengetahuan sebelum & 1,65 & 0,000 \\
\cline { 1 - 2 } Pengetahuan sesudah & 1,98 & \\
$\begin{array}{c}\text { Sumber data primer 2018 } \\
\text { Berdasarkan tabel }\end{array}$ & 4.7 & dengan \\
menggunakan uji $\quad$ Wilcoxon & menunjukkan
\end{tabular}

bahwa ada perbedaan pengetahuan antara sebelum dan sesudah diberi penyuluhan kesehatan melalui media Leaflet bahasa daerah dimana nilai $P=0,000 \leq \alpha=0,05$. Penelitian dilakukan sebelum dan sesudah diberi penyuluhan, diketahui nilai mean sebelum dilakukan penyuluhan 1,65 dan sesudah diberi penyuluhan dengan nilai mean 1,98. Dapat disimpulkan bahwa ada pengeruh secara signifikan antara penyuluhan menggunakan media leaflet bahasa daerah terhadap pengetahuan bahaya rokok pada remaja deidesa Kala'be kecamatan Aralle kabupaten Mamasa

Hasil Uji Wilcoxon untuk mengetahui pengaruh penggunaan media leaflet bahasa daerah dan media video bahasa daerah sebelum dan sesudah melakukan penyuluhan tentang bahaya rokok pada remaja dapat dilihat pada tabel dibawah ini:

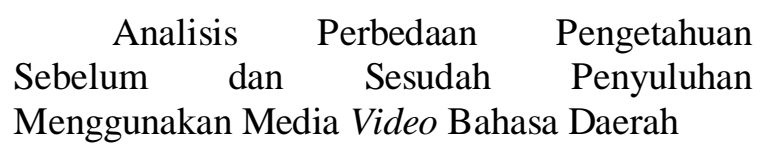

Tabel 4.8

Efektifitas Penggunaan Media Video Bahasa Daerah Dalam Meningkatkan Pengetahuan Bahaya Rokok Pada Remaja di Desa Kala'be Kec. Aralle Kab. Mamasa

Kelompok Media Video $\quad M e a \quad P$
Bahasa Daerah

\begin{tabular}{crr}
\hline Pengetahuan sebelum & 1,37 & \multirow{2}{*}{0,000} \\
\cline { 1 - 2 } Pengetahuan sesudah & 2,32 & \\
\cline { 1 - 2 } Sumber $:$ Data Primer 2018 &
\end{tabular}

Sumber : Data Primer 2018

Berdasarkan tabel 4.8 dengan menggunakan uji Wilcoxon menunjukkan bahwa ada perbedaan pengetahuan antara sebelum dan sesudah diberi penyuluhan kesehatan melalui media Video bahasa daerah dimana nilai $P=0,000 \leq \alpha=0,05$. Penelitian dilakukan sebelum dan sesudah diberi penyuluhan, diketahui nilai mean sebelum dilakukan penyuluhan 1,37 dan sesudah diberi penyuluhan dengan nilai mean 2,32. Dapat disimpulkan bahwa ada pengaruh secara signifikan antara penyuluhan menggunakan media video bahasa daerah terhadap pengetahuan bahaya rokok pada remaja deidesa Kala'be kecamatan Aralle kabupaten Mamasa

Tabel 4.7 dan tabel 4.8 menunjukkan ada pengaruh pemberian penyuluhan kesehatan tentang bahaya rokok dengan media leaflet 
bahasa daerah dan video bahasa daerah terhadap pengetahuan remaja tentang bahaya rokok di desa Kala'be kecamatan Aralle Kabupaten Mamasa. Ada perbedaan efektifitas media leaflet bahasa daerah dan video bahasa daerah terhadap pengetahuan remaja tentang bahaya rokok, diketahui mean sesudah penyuluhan

\section{PEMBAHASAN}

Hasil penelitian ini menunjukkan ada perbedaan pengaruh pendidikan kesehatan melalui media leaflet bahasa daerah dan media video bahasa daerah tentang bahaya rokok pada pengetahuan remaja di desa Kala'be kecamatan Aralle Kabupaten Mamasa.

Pada penelitian ini peneliti beragumentasi bahwa Adanya perbedaan yang mengenai pengaruh penyuluhan kesehatan menggunakan media video bahasa daerah dengan media leaflet bahasa daerah terhadap peningkatan pengetahuan remaja tentang bahaya rokok ini bisa disebabkan oleh perbedaan media yang diberikan, karena media merupakan alat yang digunakan untuk mempermudah penerimaan informasi. Dalam penyuluhan menggunakan media video bahasa daerah, informasi yang disampaikan berupa suara dan gambar yang bisa diterima dua indra sekaligus antara penglihatan dan pendengaran.

Penggunaan media video bahasa daerah menjadi lebih menarik perhatian responden sehingga membangkitkan antusiasme responden untuk medapatkan informasi dan juga lebih mudah diterima. Sedangkan penyuluhan menggunakan media leaflet bahasa daerah, informasi yang disampaikan berupa tulisan, sehingga hanya dibaca secara liner dan lebih difokuskan menstimulus indra penglihatan. Mungkin hal itu yang mengakibatkan rata-rata skor motivasi yang medapatkan penyuluhan dengan menggunakan media video bahasa daerah lebih tinggi dari pada media leaflet bahasa daerah.

Sesuai yang disampaikan dalam piramida Edgar dale yang menggambarkan kemampuan untuk mengingat kembali pesan-pesan dalam penyuluhan kesehatan menurut teknik dan medianya, yaitu mendengar dan melihat maka seseorang akan mengingat 50\% dari apa yang didengar dan dilihat, dan membaca akan mengingat $10 \%$ dari materi. menggunakan media leaflet bahasa daerah sebesar 1,98 sedangkan nilai mean sesudah penyuluhan media video bahasa daerah sebesar 2,32 . Dengan demikian dapat disimpulkan bahwa Video lebih efektif dalam meningkatkan pengetahuan bahaya rokok pada remaja di desa Kala'be kecamatan Aralle kabupaten Mamasa.

Hasil penelitian ini sejalan dengan penelitian yang dilakukan Prof. Dr. dr. Teguh W. Sardjono tahun 2011 tentang Perbedaan Pengaruh Penyuluhan Kesehatan Antara Menggunakan Media Audio Visual Dengan Media Cetak terhadap Peningkatan Motivasi Untuk Berhenti Merokok Pada Remaja, hasil penelitian ini menunjukkan bahwa penyuluhan kesehatan menggunakan media audio visual secara signifikan lebih efektif mengubah motivasi untuk berhenti merokok dibandingkan media cetak ( $p<0.05$, independent $T$ test).

Penelitian dini oleh Muhammad Yusuf Bachtiar tentang perbedaan pengetahuan pada penyuluhan Kesehatan metode ceramah dan media leaflet Dengan metode ceramah dan media video Tentang bahaya merokok di SMK Kasatrian solo tahun 2015, hasil penelitian ini ada pengaruh penyuluhan kesehatan terhadap pengetahuan tentang bahaya merokok pada penyuluhan kesehatan metode ceramah dan media leaflet maupun metode ceramah dan media video. Metode ceramah dan media video lebih berpengaruh terhadap peningkatan pengetahuan tentang bahaya merokok dengan selisih nilai peningkatan pengetahuan sebanyak 1,2 .

Dengan demikian hasil penelitian ini dapat disimpulkan bahwa media video bahasa daerah lebih efektif dalam meningkatkan pengetahuan remaja dibandingkan dengan media leaflet bahasa daerah tentang bahaya rokok. Meskipun keduanya sama-sama memberikan pengaruh yang signifikan. Semoga penelitian ini dapat dijadikan salah satu referensi bagi peneliti selanjutnya. Semoga dengan adanya penelitian ini dapat membantu kita khususnya bagi petugas kesehatan dan pihak terkait lainnya dalam melakukan kegiatan penyuluhan kesehatan di masyarakat tentang bahaya rokok. Bukan hanya menggunakan media yang modern namun kearifan lokal juga harus jadi bahan pertimbangan khususnya penggunaan bahasa daerah.

\section{KESIMPULAN DAN SARAN}


Ada perbedaan efektifitas media leaflet bahasa daerah dan video bahasa daerah terhadap pengetahuan bahaya rokok pada remaja, diketahui mean sesudah penyuluhan menggunakan media leaflet bahasa daerah sebesar 1,98 sedangkan nilai mean sesudah penyuluhan media video bahasa daerah sebesar 2,32. Dengan demikian dapat disimpulkan bahwa media video bahasa daerah lebih efektif terhadap peningkatan pengetahuan bahaya rokok pada remaja di desa Kala'be kecamatan Aralle kabupaten Mamasa.

\section{DAFTAR PUSTAKA}

Abd. Nasir, dkk. (2011). Buku Ajar Metodologi Penelitian Kesehatan: Konsep Pembuatan Karya Tulis dan Thesis untuk Mahasiswa Kesehatan. Yogyakarta: Nuha Medika.

Adi, Rian Pamungkas, A. M. U. (2017). Metodologi Riset Keperawatan. Jakarta: CV. Trans Info Media.

Al-Mukaffi, A. (2009). 1001 cara berhenti merokok . Jakarta: PT Darul Falah.

Asi, T., Di, E., \& Sambas, K. (2015). Volume 2, Nomor 1 Juli 2015, 2, 43-51.

Aliruddin.2017. Badan Pusat Statistik Kabupaten Mamasa

Fini Trisa, 2015 Implementasi Pembelajaran Bahasa Sunda Di Taman Kanak - Kanak Universitas Pendidikan Indonesia | repository.upi.edu | perpustakaan.upi.edu

Heryani.2014. Bab II tinjauan pustaka.pdf. diakses tanggal Di akses tanggal 28 Desember 2017

Hidayat, A. A. 2007. Metode Penelitian Keperawatan dan Tekhnik Analisis Data. Jakarta: Salemba Medika

Kementrian Kesehatan Indonesia. 2010. Panduan Promosi Perilaku Tidak Merokok. Kementrian Kesehatan.Jakarta.

Marisa, at. A. (2015). (2015).media pembelajaran . Tangerang Sealatan:
Universitas Terbuka.

Masdar. M. 2015. Kamus Bahasa Daerah Aralle-Indonesia

Notoadmojo. 2010. Metodologi Penelitian Kesehatan. Jakarta: PT Rineka Cipta.

Notoatmodjo, S., Hassan, A.,Hadi, EN., Krianto, T. 2012. Promosi Kesehatan di Sekolah. Jakarta :Rineka Cipta.

Nursalam \& Efendi, F. 2008. Pendidikan Dalam Keperawatan. Salemba Medika. Jakarta

Riskesdas. 2013. Riset Kesehatan Dasar. Jakarta : Badan Penelitian dan Pengembangan Kesehatan Kementerian Kesehatan RI

Suiraoka \& Supariasa .2012. Media Pendidikan Kesehatan. Yogyakarta : Graha Ilmu

Saryono. (2011). Metodologi Penelitian Kesehatan Penuntun Praktis Bagi Pemula. (A. Setiawan, Ed.). Yogyakarta: Mitra Cendekia Press.

Siti kalsum, 2015. Dalam SKRIPSI Hubungan Pola Asuh Dengan kepribadian Anak Remaja Usia 15-18 Tahun Di Sekolah Madrasah Aliyah DDI Kanang Kecamatan Binuang Kabupaten Polewali Mandar

Setiawan, Ari, S. (2011). Metodologi Penelitian Kebidanan DIII, dIV, S1, dan S2. (S. Nuha, Ed.) (ed. 3). Yogyakarta: Nuha Medika.

Tondo, F. H. (2009). Kepunahan BahasaBahasa Daerah: Faktor Penyebab Dan Implikasi Etnolinguistis. Jurnal Masyarakat \& Budaya, 11(2), 277-296.

Wibowo, R. A., Sosiologi, J., Ilmu, F., Dan, S., Politik, I., \& Maret, U. S. (2009). Pengetahuan sikap dan tindakan sosial remaja dalam kaitannya dengan musik nasyid. 